\title{
Article \\ Hydrotalcite-Embedded Magnetite Nanoparticles for Hyperthermia-Triggered Chemotherapy
}

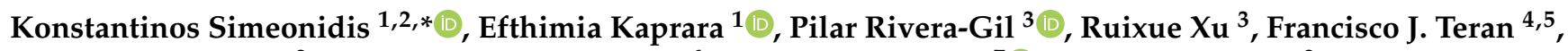 \\ Evgenios Kokkinos ${ }^{2}$, Athanassios Mitropoulos ${ }^{6}$, Nikolaos Maniotis ${ }^{7}{ }^{(D)}$ and Lluis Balcells ${ }^{8}$ \\ 1 Department of Chemical Engineering, Aristotle University of Thessaloniki, 54124 Thessaloniki, Greece; \\ kaprara@auth.gr \\ 2 Ecoresources P.C., Giannitson-Santaroza Str. 15-17, 54627 Thessaloniki, Greece; kokkinos@ecoresources.gr \\ 3 Integrative Biomedical Materials and Nanomedicine Lab, Universitat Pompeu Fabra, 08003 Barcelona, Spain; \\ pilar.rivera@upf.edu (P.R.-G.); ruixue.xu01@estudiant.upf.edu (R.X.) \\ 4 IMDEA-Nanociencia, Ciudad Universitaria de Cantoblanco, 28049 Madrid, Spain; francisco.teran@imdea.org \\ 5 Nanobiotecnología (iMdea-Nanociencia), Unidad Asociada al Centro Nacional de Biotecnología (CSIC), \\ 28049 Madrid, Spain \\ 6 Hephaestus Advanced Laboratory, Department of Chemistry, International Hellenic University, \\ 65404 Kavala, Greece; amitrop@chem.ihu.gr \\ 7 Department of Physics, Aristotle University of Thessaloniki, 54124 Thessaloniki, Greece; \\ nimaniot@physics.auth.gr \\ 8 Institut de Ciencia de Materials de Barcelona, CSIC, 08193 Bellaterra, Spain; balcells@icmab.es \\ * Correspondence: ksime@physics.auth.gr
}

Citation: Simeonidis, K.; Kaprara, E.; Rivera-Gil, P.; Xu, R.; Teran, F.J.; Kokkinos, E.; Mitropoulos, A.;

Maniotis, N.; Balcells, L.

Hydrotalcite-Embedded Magnetite

Nanoparticles for

Hyperthermia-Triggered

Chemotherapy. Nanomaterials 2021,

11, 1796. https://doi.org/10.3390/

nano11071796

Academic Editor:

Alessandro Lascialfari

Received: 7 June 2021

Accepted: 6 July 2021

Published: 9 July 2021

Publisher's Note: MDPI stays neutral with regard to jurisdictional claims in published maps and institutional affiliations.

Copyright: () 2021 by the authors. Licensee MDPI, Basel, Switzerland. This article is an open access article distributed under the terms and conditions of the Creative Commons Attribution (CC BY) license (https:// creativecommons.org/licenses/by/ $4.0 /)$.

\begin{abstract}
A magnetic nanocomposite, consisting of $\mathrm{Fe}_{3} \mathrm{O}_{4}$ nanoparticles embedded into a $\mathrm{Mg} / \mathrm{Al}$ layered double hydroxide (LDH) matrix, was developed for cancer multimodal therapy, based on the combination of local magnetic hyperthermia and thermally induced drug delivery. The synthesis procedure involves the sequential hydrolysis of iron salts $\left(\mathrm{Fe}^{2+}, \mathrm{Fe}^{3+}\right)$ and $\mathrm{Mg}^{2+} / \mathrm{Al}^{3+}$ nitrates in a carbonate-rich mild alkaline environment followed by the loading of 5-fluorouracil, an anionic anticancer drug, in the interlayer LDH space. Magnetite nanoparticles with a diameter around $30 \mathrm{~nm}$, dispersed in water, constitute the hyperthermia-active phase able to generate a specific loss of power of around $500 \mathrm{~W} / \mathrm{g}$-Fe in an alternating current (AC) magnetic field of $24 \mathrm{kA} / \mathrm{m}$ and $300 \mathrm{kHz}$ as determined by AC magnetometry and calorimetric measurements. Heat transfer was found to trigger a very rapid release of drug which reached $80 \%$ of the loaded mass within $10 \mathrm{~min}$ exposure to the applied field. The potential of the $\mathrm{Fe}_{3} \mathrm{O}_{4} / \mathrm{LDH}$ nanocomposites as cancer treatment agents with minimum side-effects, owing to the exclusive presence of inorganic phases, was validated by cell internalization and toxicity assays.
\end{abstract}

Keywords: layered double hydroxide; $\mathrm{Fe}_{3} \mathrm{O}_{4}$; continuous flow synthesis; magnetic hyperthermia; nanocomposite; drug delivery; cell internalization

\section{Introduction}

Magnetic fluid hyperthermia (MH) has been developed as an alternative approach for the heat-mediated treatment of cancer cells at a controllably localized level [1]. MH stands on the energy losses of magnetic nanoparticle (MNP) dispersion subjected to AC magnetic fields $\left(\mathrm{H}_{\mathrm{AC}}\right)$, resulting in a temperature elevation of the dispersion medium. In recent years, significant research effort has been devoted to the synthesis of MNPs with high heating efficiency, their successful incorporation into biological matrices (cells or tissues), the treatment optimization based on theoretical models and the technical improvement of field generation devices and error-free measuring protocols [2,3]. Thanks to their facile and low-cost availability in various geometries, their chemical stability, affordable biocompatibility and magnetic response, iron oxide nanoparticles are widely considered as the most efficient agents for magnetic hyperthermia applications $[4,5]$. The best heating 
efficiency for such systems is usually achieved for particle dimensions in the range of the magnetic monodomain region [6], where hysteresis losses are maximized, whereas the positive role of shape adjustment and long-scale arrangement has been demonstrated $[7,8]$. However, a major drawback for the wide adoption of magnetic hyperthermia in clinical use is the failure to validate the high heating rates of preliminary tests when nanoparticles are placed into biological environments [9]. Such inconsistency is generally attributed to the intracellular immobilisation of particles, aggregation effects on magnetic losses, heat flow dynamics or chemical modification of nanoparticles and degradation effects caused by the dissolution activity of buffer solutions on solid phases [10].

Still, systemic therapies such as those using one or more anticancer drugs introduced into the blood stream, remain in the front line of treatment strategies. Chemotherapy is normally based on the cytotoxic effect of specific molecules which inhibit the division of rapidly growing cells, such as the cancer ones. Unfortunately, the activity of these drugs is not confined to the cancer cells but they can harm any other healthy tissue type with a high dividing rate. Apart from relevant side-effects, another disadvantage of curative chemotherapy is its inability to localize its therapeutic action only on the tumor area, which implies the need of increasing the effective dose of drugs, while, as mentioned above, it can also harm healthy tissues. In order to improve the efficiency of chemotherapy, its conjunction with other modalities such as surgery, radiation and hyperthermia therapy is commonly applied.

Recently, the combination of magnetic hyperthermia with simultaneous drug delivery has been widely studied as an adjuvant therapy to enhance the permeability of anticancer molecules flowing into the blood [11]. This is generally implemented by the attachment of drug molecules onto the surface of magnetic nanoparticles which enables their direction to a specific site by the proper application of an external magnetic field. The grafting of anticancer molecules onto nanoparticles is commonly realized through chemically adsorbed organic compounds including natural biopolymers such as chitosan, polysaccharides, cellulose, lipids, micelles and copolymers. The loading capacity of these ligands with respect to the nanoparticle mass is relatively low and therefore, losses during transfer become significant. Additionally, in the effort to achieve the required dose, sometimes toxicity issues may arise.

Inorganic phases (silica, carbon, metal hydroxides) have also been proposed as drug loading agents indicating higher loading capacities, good stability and biocompatibility [12,13]. Their ability to host anticancer drugs lies on the high surface charge which facilitates strong binding into the crystal structure. More specifically, layered double metal hydroxides (LDH) with multilayer structure provide an ideal substrate to stabilize large quantities of anionic forms taking advantage of their whole volume and not just the surface area [14-17]. Beyond the significant increase of loading capacity for pharmaceutic molecules, LDH are preferable also for their low synthesis cost through aqueous precipitation methods from metals salts. The general formula of $\mathrm{LDH}$ is $\left[\mathrm{M}^{2+}{ }_{1-\mathrm{x}} \mathrm{N}^{3+}{ }_{\mathrm{x}}(\mathrm{OH})_{2}\right]^{\mathrm{x}+}\left(\mathrm{A}^{\mathrm{m}-}\right)_{\mathrm{x} / \mathrm{m}} \cdot \mathrm{nH}_{2} \mathrm{O}$, $\mathrm{M}$ : bivalent metal, $\mathrm{N}$ : trivalent metal, $\mathrm{A}$ : interlayer anions, $\mathrm{m}$ and $\mathrm{n}$ integer numbers, and $\mathrm{x}$ a number between 0-1 [18]. Several studies report the substitution of the interlayer anions by anti-inflammatory, cardiovascular and anticancer drugs either by introducing the pharmaceutics during synthesis or by postpreparation ion-exchange and reconstruction $[16,19,20]$. The most studied cases are $\mathrm{Mg} / \mathrm{Al}$ and $\mathrm{Zn} / \mathrm{Al} \mathrm{LDH}$ stabilized with carbonate, chloride or nitrate ions [21-23].

Hybrid magnetic/LDH nanostructures loaded with therapeutic drugs have been developed with the aim of promoting targeted drug delivery [24]. For instance, $\mathrm{MgFe}_{2} \mathrm{O}_{4}$ nanoparticles were coated by a $\mathrm{Mg}-\mathrm{Al}-\mathrm{NO}_{3} \mathrm{LDH}$ and then loaded with ibuprofen or glucuronate [25]. Magnesium ferrite nanoparticles combined with Mg-Al or Zn-Al LDH were also tested as host systems for 5-aminosalicylic acid, diclofenac and ibuprofen [26-28]. In several other examples, $\mathrm{Fe}_{3} \mathrm{O}_{4}$ nanoparticles served as the $\mathrm{Mg}$-Al LDH substrate and the system was loaded with fluvastatin and ibuprofen $[29,30]$. For the same nanocomposite, the loading capacity for anticancer doxifluridine was significantly high, reaching 9.7\% [31]. 
In all these cases, magnetic featuring of the drug-loaded nanocomposites was only used for the magnetically assisted delivery through the application of a static magnetic field.

Here, we report an attempt to illustrate the potential incorporation of inorganic magnetic nanohybrids, consisting of $\mathrm{Fe}_{3} \mathrm{O}_{4}$ nanoparticles and $\mathrm{Mg}$-Al LDH loaded with anticancer 5-fluorouracil $\left(\mathrm{C}_{4} \mathrm{H}_{3} \mathrm{FN}_{2} \mathrm{O}_{2}, \mathrm{FU}\right)$, as a way to improve therapeutic efficiency by combining magnetic hyperthermia and chemotherapy. Importantly, a major milestone was to go beyond the parallel occurrence of the two therapeutic modalities as described elsewhere for doxorubicin-loaded nanocomposites [32], and provide their coupling, i.e., the drug release switch-on upon application of the AC magnetic field (Figure 1). The main advantage of the proposed nanocomposites is their fully inorganic nature which is able to combine the heating capability of magnetic nanoparticles with the drug hosting capacity of the layered double hydroxide, considering also that the $\mathrm{Mg}$ / Al layered double hydroxide is already recognized for its compatibility for human use as an antacid.

HYPERTHERMIA

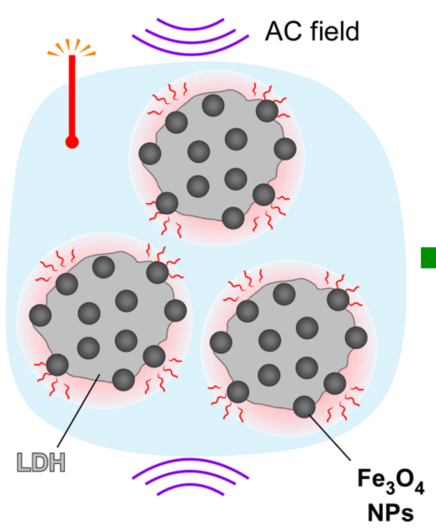

DRUG RELEASE

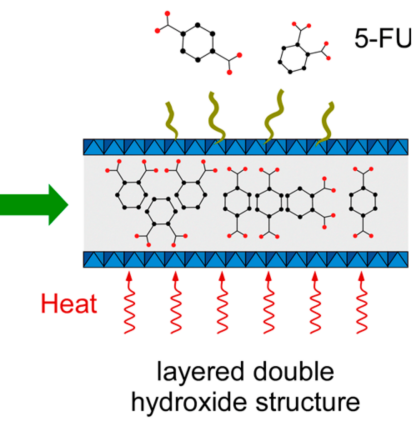

Figure 1. Graphical concept of controllable 5-fluorouracil release from the $\mathrm{Fe}_{3} \mathrm{O}_{4} / \mathrm{Mg}-\mathrm{Al} \mathrm{LDH}$ nanocomposite when exposed to a radiofrequency AC magnetic field.

\section{Materials and Methods}

\subsection{Nanocomposite Synthesis}

The synthesis of the nanocomposite consisting of $\mathrm{Fe}_{3} \mathrm{O}_{4}$ nanoparticles (IONPs) distributed into a matrix of $\mathrm{Mg} / \mathrm{Al}$ layered double hydroxide was carried out in a continuousflow sequence of two stirring reactors (operating volume $1 \mathrm{~L}$ ) by the combined precipitation of iron, magnesium and aluminium salts (Figure S1). In the first reactor, $\mathrm{Fe}_{3} \mathrm{O}_{4}$ seeds were prepared after the coprecipitation of $\mathrm{FeSO}_{4} \cdot 7 \mathrm{H}_{2} \mathrm{O}$ and $\mathrm{Fe}_{2}\left(\mathrm{SO}_{4}\right)_{3} \cdot 9 \mathrm{H}_{2} \mathrm{O}$, which were pumped in the form of aqueous solutions $(5 \mathrm{mM})$, under alkaline conditions ( $\mathrm{pH} 11)$ regulated by the continuous addition of $\mathrm{NaOH}$ solution $(2 \mathrm{~g} / \mathrm{L})$ in drops. The blackcoloured suspension was directed into the second reactor in which the coprecipitation of $\mathrm{Mg}\left(\mathrm{NO}_{3}\right)_{2} \cdot 6 \mathrm{H}_{2} \mathrm{O}$ and $\mathrm{Al}\left(\mathrm{NO}_{3}\right)_{3} \cdot 9 \mathrm{H}_{2} \mathrm{O}$ took place. The two reagents were pumped as aqueous solutions with concentration $10 \mathrm{mM}$ and hydrolyzed at a $\mathrm{pH} 9$ maintained by the addition of a 1:1 mixture of $\mathrm{NaOH} / \mathrm{Na}_{2} \mathrm{CO}_{3}(3.5 \mathrm{~g} / \mathrm{L})$. Sodium carbonate was introduced in this step to serve also as the source of $\mathrm{CO}_{3}{ }^{2-}$ which participated in the building up of the layered hydrotalcite structure. Each reactor operated with a residence time of $1 \mathrm{~h}$. The final product was received in the outflow of the second reactor and then, centrifuged and washed several times to remove soluble residuals. The described reactions can be realized with similar success in batch reactors, however, advantages such as the good reproducibility, the achievement of constant concentrations in all ionic and solid forms, the minimization of operation cost and the scale-up potential to mass production would not be covered. A schematic summary of the process is presented in Figure 2 while a picture of the laboratory continuous-flow system appears in Supplementary Materials. 


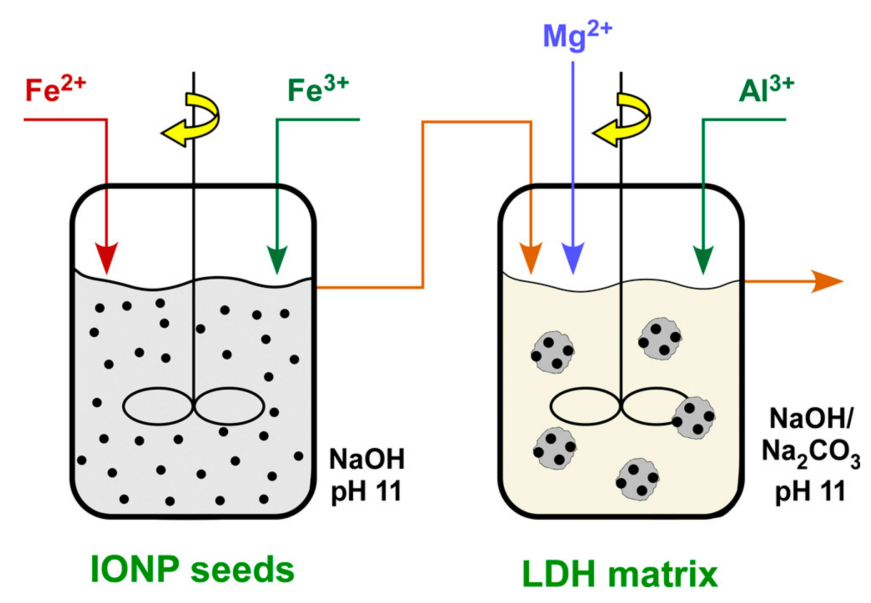

Figure 2. Continuous-flow reactor sequence for the production of the $\mathrm{Fe}_{3} \mathrm{O}_{4} / \mathrm{Mg}-\mathrm{Al} \mathrm{LDH}$ nanocomposite.

The weight percentage of magnetite nanoparticles in the nanocomposite and the Mg-to-Al molecular ratio in the layered double hydroxide were determined by properly modifying the reagents' flowrates. For instance, to receive a nanocomposite with $35 \mathrm{wt} . \%$ in $\mathrm{Fe}_{3} \mathrm{O}_{4}$ nanoparticles (MagnoTher, MGT-35), both $\mathrm{FeSO}_{4}$ and $\mathrm{Fe}_{2}\left(\mathrm{SO}_{4}\right)_{3}$ flowrates were adjusted to $0.1 \mathrm{~L} / \mathrm{h}$ while $\mathrm{Mg}\left(\mathrm{NO}_{3}\right)_{2}$ and $\mathrm{Al}\left(\mathrm{NO}_{3}\right)_{3}$ were added with a flowrate of 0.24 and $0.08 \mathrm{~L} / \mathrm{h}$, respectively. To decrease $\mathrm{Fe}_{3} \mathrm{O}_{4}$ content at $20 \mathrm{wt}$ \% (MagnoTher, MGT-20), $\mathrm{Mg}\left(\mathrm{NO}_{3}\right)_{2}$ and $\mathrm{Al}\left(\mathrm{NO}_{3}\right)_{3}$ flowrates were increased to 0.45 and $0.15 \mathrm{~L} / \mathrm{h}$, respectively. Using such proportions, the Mg-to-Al molecular ratio was adjusted to 3. Under such conditions, the production rate of the nanocomposite in terms of dry solid varied between $0.35-0.55 \mathrm{~g} / \mathrm{h}$.

\subsection{Characterization}

An overview of produced nanocomposites' morphology and separately of their constituting phases was obtained by electron microscopy. For more clarity on the distribution of IONPs, high magnification images were taken by transmission electron microscopy (TEM) using JEM-1210 (JEOL, Tokyo, Japan), operating at $120 \mathrm{kV}$. TEM samples were prepared by dropping a diluted aqueous dispersion of the material onto a carbon coated copper grid. Quasi-static magnetic properties of the samples were measured using a superconducting quantum interference device (SQUID) MPMS XL-7T magnetometer (Quantum Design, San Diego, CA, USA). Structural-phase identification was performed by powder X-ray diffractometry (XRD) using a water-cooled Ultima+ diffractometer (Rigaku, Tokyo, Japan) with CuKa radiation, a step size of $0.05^{\circ}$ and a step time of $3 \mathrm{~s}$, operating at $40 \mathrm{kV}$ and $30 \mathrm{~mA}$.

Average elemental content of the nanocomposites was determined by graphite furnace atomic absorption spectrophotometry, using a AAnalyst 800 instrument (Perkin Elmer, Waltham, MA, USA). The actual ratio of $\mathrm{Fe}^{2+} / \mathrm{Fe}^{3+}$ in the $\mathrm{Fe}_{3} \mathrm{O}_{4}$ fraction was defined after digestion of a weighted quantity of each sample in $7 \mathrm{M} \mathrm{H}_{2} \mathrm{SO}_{4}$ under heating and titration with $0.05 \mathrm{M} \mathrm{KMnO}_{4}$ solution till the appearance of a pink colour. The percentage of carbonates $\left(\mathrm{CO}_{3}{ }^{2-}\right)$ located in the interlayer space of hydrotalcite was quantified using a FOGL bench-top soil calcimeter (BD Inventions, Thessaloniki, Greece) with a determination error of less than $5 \%$.

The potentiometric mass titration method was applied to define the positive charge density of the solid. In the first step, the point of zero charge (PZC) was determined after equilibrating water suspensions of the nanocomposites $(10 \mathrm{~g} / \mathrm{L})$ in $0.001,0.01$ and $0.1 \mathrm{M}$ $\mathrm{NaNO}_{3}$ solutions and adjusting $\mathrm{pH}$ to 11 by adding $0.1 \mathrm{M} \mathrm{NaOH}$. Then, suspensions were titrated by adding stepwise small quantities of a $0.1 \mathrm{~N} \mathrm{HNO}_{3}$ solution and recording equilibrium $\mathrm{pH}$ until $\mathrm{pH} 3$ was reached. For the three ionic strengths, the plotting of surface charge density, which is proportional to the difference of acid volume used to set the same $\mathrm{pH}$ in the dispersion and a blank titration, indicates the PZC as the point of intersection. 


\subsection{Magnetic Heat Losses}

Calorimetry measurements of magnetic suspensions under $\mathrm{H}_{\mathrm{AC}}$ were performed using a commercial AC magnetic field generator (SPG-06-III 6 kW High Frequency Induction Heating Machine, Shenzhen Shuangping Ltd., Shenzhen, China) working at $765 \mathrm{kHz}$ frequency and $24 \mathrm{kA} / \mathrm{m}$ magnetic field intensity. The specific loss power (SLP), referred to as specific absorption rate (SAR) hereafter, was derived from the slope of the temperature versus time curve after subtracting water background signal and heat losses to the environment [33].

Temperature variations during the application of AC field were recorded using a commercial optical fibre thermal probe located in the centre of the sample and connected to an PicoM device (Opsens, Quebec, QC, Canada) with an experimental error of $\pm 0.1^{\circ} \mathrm{C}$. $\mathrm{SAR}$ values under non-adiabatic conditions were determined through the temperature increment as a function of time (dT/dt) using the following expression:

$$
\mathrm{SAR}=\frac{\mathrm{C}_{\mathrm{d}} \mathrm{m}_{\mathrm{d}}}{\mathrm{m}_{\mathrm{Fe}}} \frac{\mathrm{dT}}{\mathrm{dt}}
$$

where $C_{d}$ is the mass specific heat of the dispersion media, $m_{d}$ is the dispersion's mass, $\mathrm{m}_{\mathrm{Fe}}$ is the iron mass related to the IONPs diluted in the dispersion and $\mathrm{dT} / \mathrm{dt}$ is the effective slope upon switching $\mathrm{H}_{\mathrm{AC}}$ on, after subtracting the contributions of coil surface heating and environment cooling. The value of $C_{d}$ considered in this study was $4.18 \mathrm{~J} / \mathrm{g} \mathrm{K}$ for water dispersion.

AC magnetometry measurements of the magnetic colloids were carried out by commercial inductive magnetometers (AC Hyster Series; Nanotech Solutions, Madrid, Spain). The AC Hyster Series magnetometer offers a wider field frequency range from $10 \mathrm{kHz}$ up to $300 \mathrm{kHz}$ and field intensities up to $24 \mathrm{kA} / \mathrm{m}$ which are automatically selected. Hyster Series measure magnetization cycles from IONPs dispersed in liquid media at room temperature, consisting of three repetitions to obtain an average of the magnetization cycles and the related magnetic parameters $\left(\mathrm{H}_{\mathrm{C}}, \mathrm{M}_{\mathrm{R}}\right.$, Area). In order to accurately quantify the magnetic losses of IONP suspensions, the specific absorption rate (SAR) values were calculated according to SAR $=A \cdot f$, where $A$ is the magnetic area and $f$ is AC magnetic field frequency [34].

\subsection{Drug Loading and Release}

Loading of 5-fluorouracil in the interlayer space of the $\mathrm{Mg}$-Al LDH part of the nanocomposite was carried out by equilibrating a quantity of the samples with a solution of the drug in phosphate-buffered saline (PBS). The obtained FU-loaded nanocomposite sample is referred as $\mathrm{Fe}_{3} \mathrm{O}_{4} / \mathrm{LDH}-\mathrm{FU}$. In these experiments, a freshly prepared $20 \mathrm{mM}$ stock solution of 5-fluorouracil in PBS was used after proper dilution. Exchange between 5-fluorouracil molecules and carbonates was maximized when experiment took place at $\mathrm{pH}$ 9. In these conditions, the kinetic behavior of loading was studied using a $2 \mathrm{~g} / \mathrm{L}$ dispersion of MGT-35 in a $0.5 \mathrm{mM} 5$-fluorouracil PBS solution and measuring the residual concentration in different time intervals till equilibrium was reached. The adsorption capacity variation (isotherm) as a function of residual 5-fluorouracil was determined after equilibrating 2-20 g/L of nanocomposite with a $15 \mathrm{mM}$ drug solution.

After drug loading, the leaching behavior under different $\mathrm{pH}$ values was evaluated. Sample loaded with around $1 \mathrm{mmol} / \mathrm{g}$ of 5 -florouracil was dispersed in PBS adjusted to $\mathrm{pH}$ 4.0, 7.4 and 8.5, and the released drug was monitored for a period of up to $60 \mathrm{~min}$. Similarly, the release of drugs was examined for various temperatures, 10,20 and $35^{\circ} \mathrm{C}$, while in another experiment the temperature of the sample was increased at $40^{\circ} \mathrm{C}$ by the application of AC magnetic field and kept at this value for $10 \mathrm{~min}$.

\subsection{Cell Internalization}

Human colon cancer cells (HT29) were cultured in a microscope coverslip placed in the wells of a 12-well plate containing DMEM/F-12 (Dulbecco's Modified Eagle Medium/Nutrient 
Mixture) basal medium supplemented with 10\% fatal bovine serum (FBS), 1\% l-glutamine and $1 \%$ penicillin/streptomycin. After $24 \mathrm{~h}$, they were incubated with the nanoparticles (IONPs, $\mathrm{Fe}_{3} \mathrm{O}_{4} / \mathrm{LDH}$ and $\mathrm{Fe}_{3} \mathrm{O}_{4} / \mathrm{LDH}-\mathrm{FU}$ ) at a concentration of $0.1 \mathrm{mg} / \mathrm{mL}$ in growth media for two days. Then, the cells were washed and incubated with lysotracker red $(0.25 \mu \mathrm{M}$ dispersed in basal media for $25 \mathrm{~min})$ to stain the lysosomes. The cells were then washed with PBS, dispersed in PBS and observed under a LSP2 Leica Confocal Laser Scanning Microscope. Samples were excited with a $543 \mathrm{~nm}$ Green Helium-Neon laser and collected emitted light from $555 \mathrm{~nm}$ to $620 \mathrm{~nm}$.

\subsection{Toxicity}

A resazurin-based cytotoxicity assay was used for checking the biocompatibility of the nanoparticles (IONPs and Mg-Al LDH-FU) in HT29. A number of 20,000 cells / well in $100 \mu \mathrm{L}$ growth medium were seeded in a 96-well plate. After growth for two days, cells were incubated with different nanoparticle concentrations ranging from 0 to $256 \mathrm{mg} / \mathrm{mL}$ for one day. As negative control for cell viability, cells were incubated with dimethyl sulfoxide (DMSO) inducing cell death. Three wells were used per sample tested. Afterwards, resazurin $(10 \%)$ was added for three hours and measured for its fluorescent metabolite (resorufin) $\left(\lambda_{\mathrm{ex}} 560 \mathrm{~nm} ; \lambda_{\mathrm{em}} 572-650 \mathrm{~nm}\right.$ ). First, the maximum intensity emission wavelength value was taken and the maximum intensity value obtained for the negative control to remove background signal was subtracted. Then, data was normalized with the highest value. Finally, the normalized values (relative cell viability, \%) were plotted towards the logarithm of the concentrations. GraphPad Prism 6 was used to obtain the $\log \mathrm{IC}_{50}$. This experiment was replicated three times.

\section{Results and Discussion}

\subsection{Material Properties}

The structural characterization of the developed nanocomposite indicated the preservation of the constituting phases, $\mathrm{LDH}$ and iron oxide, in the final product. Figure 3 shows the XRD diagrams of the pure components when separately prepared in comparison to their sequential preparation as a hybrid in the two-stage reaction setup. The observed diffraction peaks for IONPs fitted well to those expected for the inverse spinel structure of $\mathrm{Fe}_{3} \mathrm{O}_{4}$ whereas the layered formation of the $\mathrm{Mg}-\mathrm{Al} \mathrm{LDH}$ was signified by the strong low-angle peaks which were identified as hydrotalcite. Chemical analysis indicated that $\mathrm{Mg} / \mathrm{Al}$ molecular ratio was 2.9/1 which is very close to the nominal value for the $\mathrm{R} 3 \mathrm{~m}$ space group of hydrotalcite. For initially formed hydrotalcite, the unit cell parameters of its 3R stacking sequence were calculated to be $\alpha=0.3055 \mathrm{~nm}$ and $\mathrm{c}=2.2725 \mathrm{~nm}$ respectively, whereas the interlamellar distance estimated by the reflection (003) was found to be $0.7755 \mathrm{~nm}$. Such a value is determined by the hosted structural carbonates which reached a percentage of $14.0 \mathrm{wt}$ \% in the $\mathrm{Mg}-\mathrm{Al} \mathrm{LDH}$.

The presence of $\mathrm{Fe}_{3} \mathrm{O}_{4}$ instead of $\gamma-\mathrm{Fe}_{2} \mathrm{O}_{3}$ as the dominant iron oxide was verified after determination of the $\mathrm{Fe}^{2+} / \mathrm{Fe}^{3+}$ ratio at around 0.41 very close to the expected stoichiometry for magnetite (0.5). Overall, the chemical analysis indicated the percentages of Fe: 22.7 wt.\%, Mg: 13.5 wt.\%, Al: 7.2 wt.\% for sample MGT-20 and Fe: 39.8 wt.\%, Mg: 11.0 wt.\%, Al: $6.1 \mathrm{wt} \% \%$ for sample MGT-35 which came in good agreement to the targeted mass ratio for the $\mathrm{LDH}$ and $\mathrm{Fe}_{3} \mathrm{O}_{4}$ phases in the nanocomposites.

The nanocomposites showed relatively high specific surface areas, $78 \mathrm{~m}^{2} / \mathrm{g}$ for MGT-20 and $65 \mathrm{~m}^{2} / \mathrm{g}$ for MGT-35, although they appeared significantly decreased in comparison to the pure $\mathrm{Mg}-\mathrm{Al} \mathrm{LDH}\left(175 \mathrm{~m}^{2} / \mathrm{g}\right)$. The nanocomposites indicated also a significant surface charge density which was maintained at around $0.7 \mathrm{mmol} \mathrm{OH}^{-} / \mathrm{g}$. 


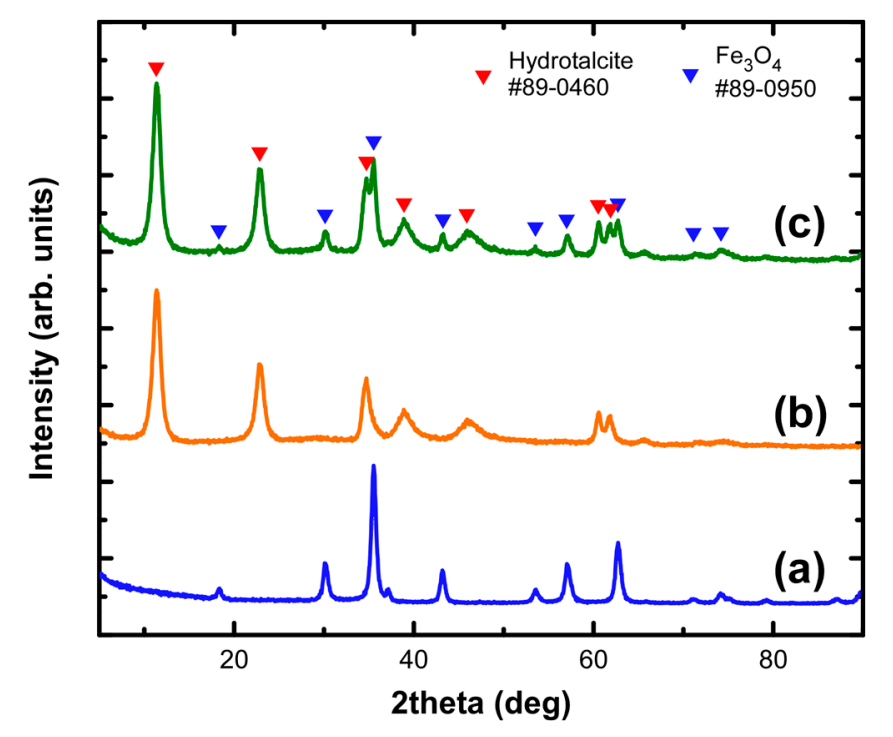

Figure 3. XRD diagrams of the IONPs (a), pure hydrotalcite (b) and MGT-35 (c).

The TEM images shown in Figure 4 provide a representative view on the nanoscale morphology and distribution of the nanocomposites in comparison to the separately prepared pure LDH and IONPs. Following the described precipitation method, Mg-Al LDH form very thin nanosheets, while IONPs have a nearly spherical shape with an average diameter of $31 \pm 6 \mathrm{~nm}$. The sequential synthesis of the two phases resulted in a good distribution of the nanoparticles onto the surface of the LDH sheets. Magnetic interactions between nanoparticles and the absence of any stabilizing agent during synthesis contributed to the observed aggregation effects. The lower magnification images of the sample MGT-35 (Figure S7), recorded with scanning electron microscopy, indicate that in the powder form, the layered matrix appears as a continuous substrate without obvious limits of the separation that occurs when dispersed. This effect may be attributed to the secondary self-organization of the layered structure by weak forces during dewatering and it is fully reversible considering that a hydrodynamic diameter of samples was measured around $500 \mathrm{~nm}$.

The magnetic response of the nanocomposites was attributed to the participation of $\mathrm{Fe}_{3} \mathrm{O}_{4}$ and its intensity appeared to be proportional to the magnetic phase percentage. The hysteresis loops under quasi-static conditions shown in Figure 5 indicated that samples MGT-20 and MGT-35 had saturation magnetisation values around 17 and $30 \mathrm{Am}^{2} / \mathrm{kg}$ respectively, in good accordance to the measured magnetisation for pure IONPs $\left(90 \mathrm{Am}^{2} / \mathrm{kg}\right)$ and the mass percentage of $\mathrm{Fe}_{3} \mathrm{O}_{4}$ in each case.

\subsection{Hyperthermia Performance}

The temperature increase during the AC field application indicated a significantly high potential of the samples to deliver heat flow to the environment (Figure S3). For instance, a temperature increase from room temperature to around $35^{\circ} \mathrm{C}$ within $2 \mathrm{~min}$ of field application was obtained for a $2 \mathrm{~g} / \mathrm{L}$ aqueous dispersion of sample MGT-35, yielding a SAR value of $1970 \mathrm{~W} / \mathrm{g}_{\mathrm{Fe}}( \pm 10 \%)$. Keeping the same field strength, SAR values seemed to follow an exponentially increasing trend in the frequency range from 30 to $765 \mathrm{kHz}$ succeeding in relatively high performances even for frequencies below $100 \mathrm{kHz}$ (Figure 6). The uncertainty of the determined SAR values in the lower frequencies range was quite small (typically below 3\%) following the accuracy of the AC magnetometry measurements. Importantly, it was found that the addition of the $\mathrm{Mg}-\mathrm{Al} \mathrm{LDH}$ phase did not appear to modify the heating performance of IONPs and therefore, temperature rise was proportional to the content of the magnetic phase. 

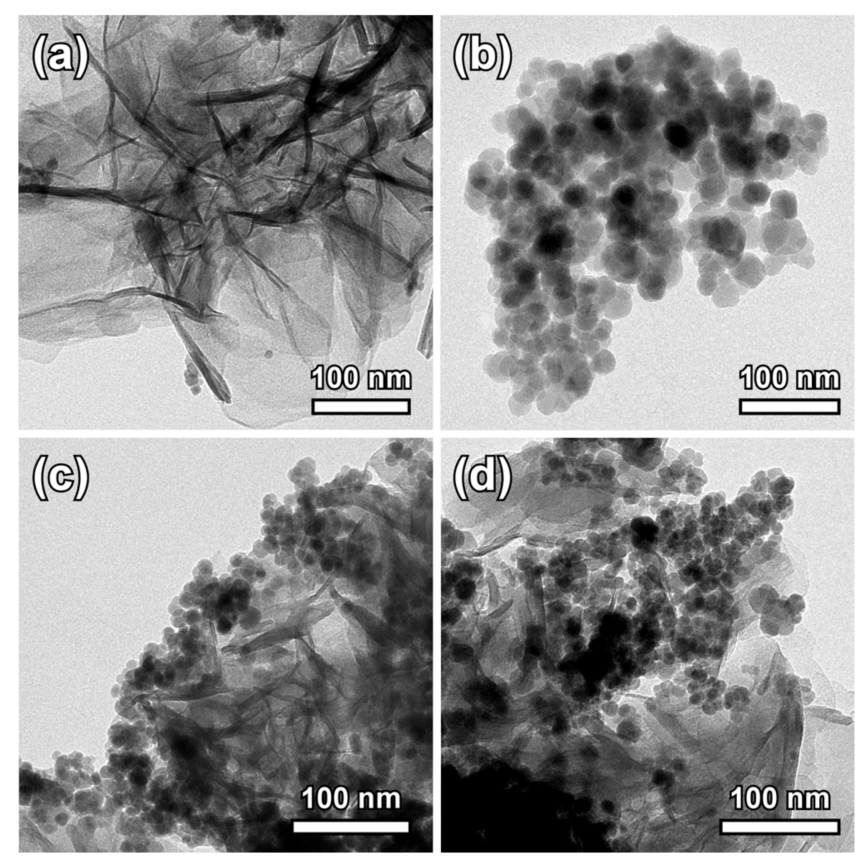

Figure 4. TEM images of the pure hydrotalcite phase (a) and the IONPs (b). Corresponding images showing the nanostructure of MGT-20 (c) and MGT-35 (d).

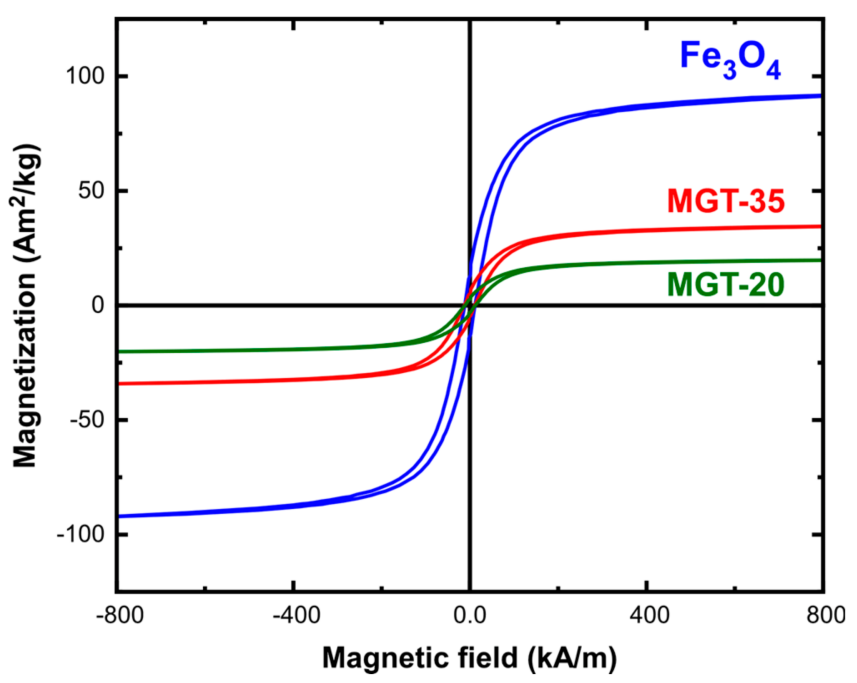

Figure 5. Magnetic hysteresis loops of MGT-20 and MGT-35 in comparison to the constituting IONPs.

Compared to other studies on single iron oxide nanoparticles or LDH composites, the obtained SAR values were among the highest reported, covering a very wide frequency range. Typically, $\mathrm{Fe}_{3} \mathrm{O}_{4}$ nanoparticles prepared by the oxidative precipitation method, showed efficiency of around $2 \mathrm{~kW} / \mathrm{g}$ at $765 \mathrm{kHz}$, translated into $2.3 \mathrm{~W} / \mathrm{g}_{\mathrm{Fe}}$ when produced by a continuous flow process [35], but less than half when produced in batches [36]. Aiming to achieve higher SAR values (up to $10 \mathrm{~kW} / \mathrm{g}$ at $500 \mathrm{kHz}$ ), combined ferrite phases were employed but the requirement for using hazardous reagents for their synthesis and the toxicity of elements such as Mn and Co inhibit their potential for clinical application [37-39]. Research reports on the heating performance of magnetic nanoparticle-decorated LDH systems are only scarce. For example, $\mathrm{Fe}_{3} \mathrm{O}_{4} / \mathrm{Mg}-\mathrm{Al} \mathrm{LDH}$ nanohybrids were found to reach an SAR of $73.5 \mathrm{~W} / \mathrm{g}$ at $425 \mathrm{kHz}$ and $30 \mathrm{kA} / \mathrm{m}$ [32]. The same study provided promising results concerning the combined hyperthermia and drug delivery with doxorubicin as well as the therapeutic efficiency in HeLa cells. 


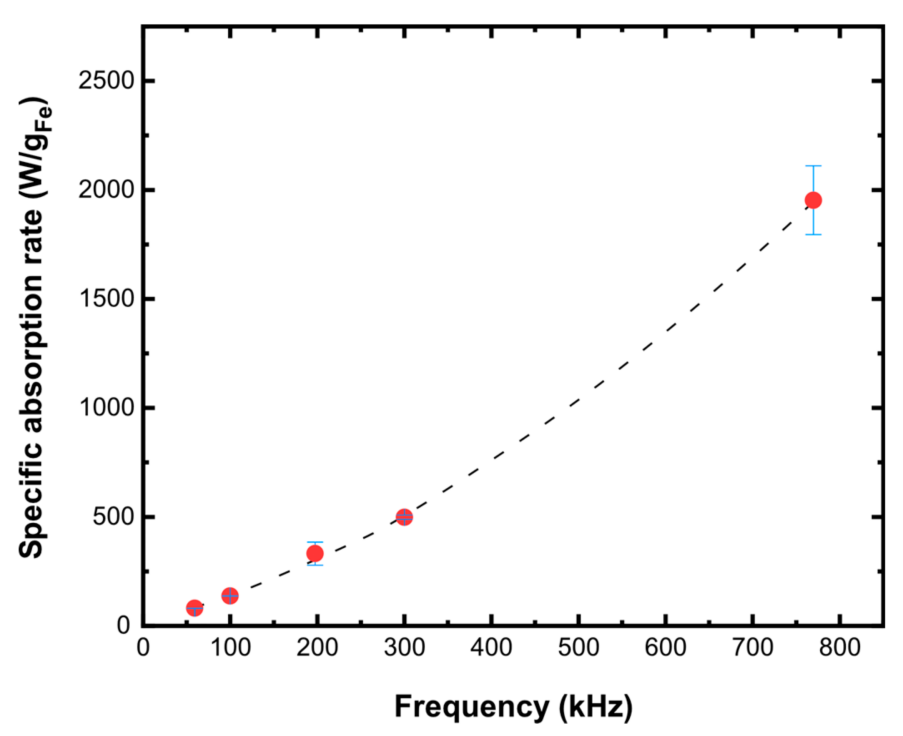

Figure 6. SAR values determined at various AC magnetic field frequencies and strength $24 \mathrm{kA} / \mathrm{m}$ for aqueous dispersions ( $2 \mathrm{~g} / \mathrm{L}$ ) of MGT-35. Dashed line is a guide to the eye.

\subsection{Drug Release Behavior}

The capacity of the Mg-Al LDH structure to host 5-fluorouracil molecules after exchange with structural carbonates was first demonstrated through the kinetic experiments (Figure S2). Within less than $1 \mathrm{~h}$, MGT-35 was able to capture significant quantities from the equilibrated drug solution overcoming a loading of $6.5 \mathrm{mmol} / \mathrm{g}$ and approaching the $75 \%$ of its maximum ability $(\sim 8.7 \mathrm{mmol} / \mathrm{g})$ into $\mathrm{PBS}$ at $\mathrm{pH}$ 9. The procedure is described as:

$$
\mathrm{Mg}_{6} \mathrm{Al}_{2}(\mathrm{OH})_{16}\left(\mathrm{CO}_{3}{ }^{2-}\right)+\mathrm{C}_{4} \mathrm{H}_{3} \mathrm{FN}_{2} \mathrm{O}_{2}{ }^{-} \rightarrow \mathrm{Mg}_{6} \mathrm{Al}_{2}(\mathrm{OH})_{16}\left(\mathrm{C}_{4} \mathrm{H}_{3} \mathrm{FN}_{2} \mathrm{O}_{2}{ }^{-}\right)+\mathrm{CO}_{3}{ }^{2-}
$$

It should be noted that the loss of carbonate content at the end of this experiment, which validates the presence of the ion exchange mechanism, was around $1 \mathrm{wt} . \%$ Considering the uptake capacity values for 5-fluorouracil, carbonate losses appeared much higher than the stoichiometrically expected ones, suggesting that the incorporation of drug's voluminous molecule caused the release of multiple carbonate ions in order to fit in the interlayer space. The partial replacement of the structural carbonates by 5 -fluorouracil was also reflected in the expansion of Mg-Al LDH unit cell which was revealed by the shift of the XRD diffractogram to smaller angles in the drug-loaded sample (Figure S6). The uptake capacity can be adjusted by varying the dispersion's concentration and therefore, the residual 5-fluorouracil concentration as shown in the adsorption isotherm of Figure S4.

The stability of loaded 5-fluorouracil and the release rate can be evaluated by modifying the $\mathrm{pH}$ of the dispersion medium (Figure S5). At pH 8.5, slightly below the loading acidity, the release rate was very low with less than $20 \mathrm{wt} . \%$ of the drug to be found in soluble state. However, the loss percentage within $1 \mathrm{~h}$ of contact, reached $50 \mathrm{wt} . \%$ when the $\mathrm{pH}$ was adjusted to 7.4. The weakening of the layered structure by the increase of metal component solubility was the reason for the increasingly observed drug release. Under more acidic conditions, the whole quantity of drug was completely released immediately, however, a significant part was captured back to the nanocomposite within less than $1 \mathrm{~h}$ of contact. The last observation could be of high importance when stimuli-responsive drug delivery systems are required.

The temperature of the studied medium was another important parameter which defined the release rate even in the short term (Figure 7). More specifically, the loading loss at temperatures of 10,20 and $35^{\circ} \mathrm{C}$ (close to the human body temperature) after $5 \mathrm{~h}$ of contact at $\mathrm{pH} 7.4$ was found to be 45,55 and $70 \mathrm{wt} . \%$, respectively. The temperature-dependence study provides a general view of the release kinetics in a wide temperature range indicating the behavior of the drug-loaded nanocomposite during storage in a refrigerator or 
its application in cancer treatment. Importantly, even at the higher temperature, around $20 \%$ of the initial load was stabilized into the nanocomposite for several hours. A very interesting finding that validates the motivation of this study was that the drug release was very rapid and reached $80 \mathrm{wt} . \%$ only by applying the AC magnetic field for $10 \mathrm{~min}$ and reaching a temperature of $40^{\circ} \mathrm{C}$ by means of magnetic hyperthermia. This result should be attributed to the high localized temperature increase within the nanocomposite mass which was able to initiate a fast release response to the LDH phase.

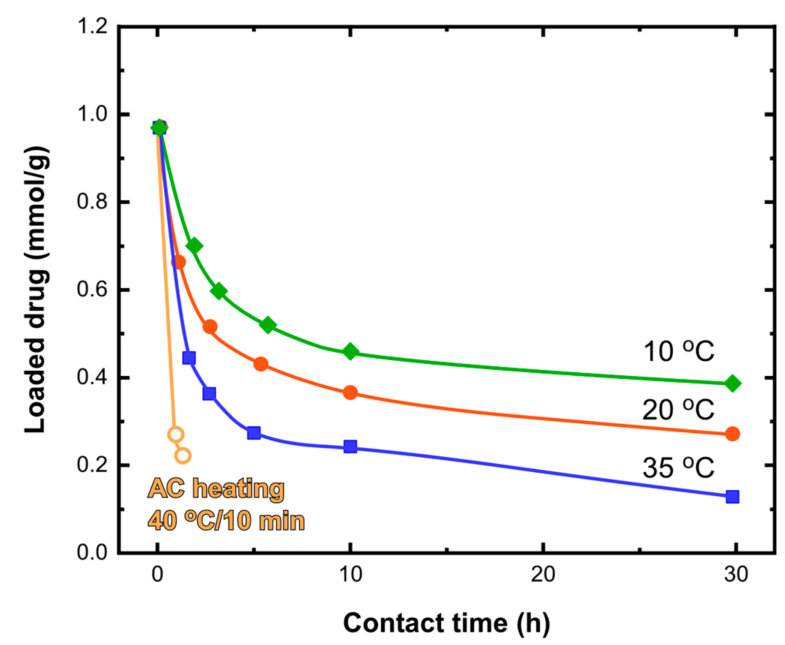

Figure 7. Drug release evolution for drug-loaded MGT-35 in PBS solution adjusted to $\mathrm{pH} 7.4$ for various temperatures and corresponding curves for keeping the dispersion at $40^{\circ} \mathrm{C}$ by applying $\mathrm{AC}$ magnetic field.

\subsection{Cellular Uptake and Biocompatibility}

The biological characterization of the pure and drug-loaded MGT-35, in comparison to the corresponding IONPs, involved cell internalization and the induced cellular toxicity. The physicochemical properties of nanoparticles (e.g., size, shape, charge) are known to affect cellular responses such as internalization (rates and mechanisms) or cytotoxicity [40-43] and, therefore, knowledge of these parameters is crucial to predict the nanoparticle potential for the magnetic hyperthermia treatment of cancer in real biological conditions that may interfere with performance. For example, previous results showed differences in the uptake of magnetic nanoparticles depending on the surface charge (positive vs. negative) [44]. Quantitative analysis indicated that positively charged magnetic nanoparticles avoid the early endosomes and they are preferentially located in the lysosomes. On the other hand, negatively charged nanoparticles were first accumulated in early endosomes and then, transferred to the lysosomes with time. In general, positively charged nanoparticles are considered as more toxic (at least, acutely) than their negatively charged counterparts due to their stronger interaction with cellular components [43,45].

HT29 cells were incubated with the three tested systems, i.e., $\mathrm{Fe}_{3} \mathrm{O}_{4}$ nanoparticles, pure MGT-35 and drug-loaded MGT-35 (MGT-35-FU). Figure 8 shows that the nanoparticles were steadily taken up by the cells located in the lysosomes after two days of incubation. The nanomaterials provided a high contrast in the transmitted channel of the confocal microscope, mostly due to a strong intracellular accumulation. This high contrast enabled their tracking inside the cells and colocalization inside the lysosomes (labelled in red). Figure 9 illustrates the toxicity profile at the level of mitochondrial activity of the three samples when exposed at different concentrations ranging from 256 to $0.5 \mathrm{mg} / \mathrm{mL}$ for $24 \mathrm{~h}$. Reference IONPs practically exhibited no toxicity at the given concentrations and exposure time. Iron oxide nanoparticles are known to be metabolized with the iron metabolism in the spleen and liver [46]. MGT-35 and MGT-35-FU showed a sigmoidal curve for toxicity. The $\mathrm{IC}_{50}$ values of $\mathrm{Fe}_{3} \mathrm{O}_{4}$, MGT-35 and MGT-35-FU, which indicate the concentrations needed for each system to kill half of the cell population, were $476 \mathrm{mg} / \mathrm{mL}, 12 \mathrm{mg} / \mathrm{mL}$, 
and $18 \mathrm{mg} / \mathrm{mL}$, respectively. It appears that the presence of the $\mathrm{Mg}-\mathrm{Al} \mathrm{LDH}$ modifies the toxicity profile of the sample, although the provided concentration range for safe use without chemically induced side-effects still remains wide. Such observations should be attributed to the relatively good structural stability which favours membrane damage and the higher release of metal ions and carbonates at the acidic conditions occurring in endosomes or lysosomes [47]. Noteworthy, MGT-35-FU and MGT-35 exhibited similar $\mathrm{IC}_{50}$ values. Their toxic profile appeared to be dominated by the $\mathrm{Mg} / \mathrm{Al}$ layered double hydroxide matrix while the effect of the 5-fluorouracil presence was minor. Such a finding was attributed to the drug release of around $80 \%$ (Figure 7) which took place during the initial washing of the nanocomposite before contact with the cells. The remaining $20 \%$ could be stabilized into the structure for the time window of the experiment, as explained by the temperature-dependent kinetic data. The application of localized heating by magnetic hyperthermia enabled this barrier to be overcome and rapidly promoted the complete release of this fraction which appeared to be the most strongly captured. Another possible explanation is that the presence of serum protein corona around the nanoparticles may influence the short-term release kinetics of 5-fluorouracil [41,44].

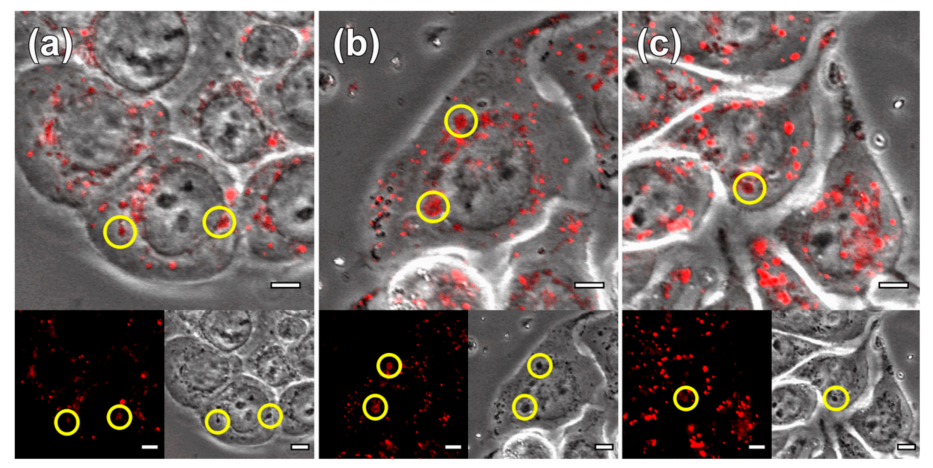

Figure 8. Internalization of $\mathrm{Fe}_{3} \mathrm{O}_{4}$ nanoparticles, (a) pure MGT-35 (b) and MGT-35-FU (c) by HT29 cells. Cells were incubated with $0.1 \mathrm{mg} / \mathrm{mL}$ nanoparticles for two days. The nanoparticles are visible due to the high contrast provided in the transmission channel (low right inset) The lysosomes of the cells were labelled with lysotracker (red dots) (low left inset). The main image corresponds to the overlay of the fluorescent (red) and transmission channel. The yellow circles mark the overlap of nanoparticles and lysosome. The scale bar represents $5 \mu \mathrm{m}$.

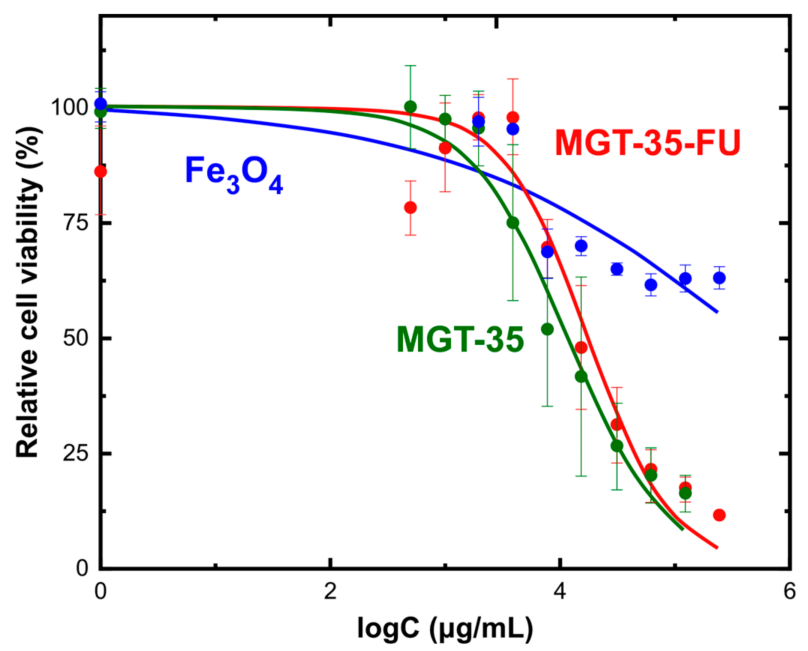

Figure 9. Cytotoxicity of HT29 cells exposed to $\mathrm{Fe}_{3} \mathrm{O}_{4}$ nanoparticles (blue line), MGT-35 (green line) and MGT-35-FU (red line). The cell viability was normalized using the highest signal measured and the percentage was plotted against the logarithm of the samples' concentration. 


\section{Conclusions}

A 100\% inorganic-based drug carrier was developed to be used for the controllable delivery and release of anticancer molecules. In particular, a nanocomposite built from iron oxide nanoparticles and a matrix of $\mathrm{Mg} / \mathrm{Al}$ layer double hydroxide was produced by an environmentally friendly and scalable procedure which provides very stable synthesis conditions, high production rates and an affordable cost for an engineered drug-delivery system. The nanocomposite is capable of loading up to several $\mathrm{mmol} / \mathrm{g}$ of anionic molecules, such as 5-fluorouracil, which is then released very rapidly when an AC magnetic field is externally applied, due to the high heat generation at the microstructure level. Importantly, such advantages are combined with sufficient cell internalization of the nanocomposite and very limited toxicity, even for relatively high applied concentrations.

Supplementary Materials: The following are available online at https: / www.mdpi.com/article / 10.3390/nano11071796/s1, Figure S1, Laboratory setup for the continuous-flow production of the hydrotalcite/magnetite nanocomposites. Figure S2, Kinetic of drug loading. Figure S3, Temperature increase during AC field application. Figure S4, Uptake capacity versus residual 5-fluorouracil concentration. Figure S5, Time dependent leaching behavior of 5-fluorouracil. Figure S6, XRD diagrams of pure hydrotalcite before and after loading with 5-fluorouracil. Figure S7, Scanning electron microscopy images and elemental analysis.

Author Contributions: Conceptualization, K.S., A.M. and E.K. (Efthimia Kaprara); methodology, P.R.-G., R.X., F.J.T., E.K. (Evgenios Kokkinos), L.B.; data curation, N.M.; writing-original draft preparation, K.S., E.K. (Efthimia Kaprara), F.J.T. and P.R.-G.; writing-review and editing, K.S., E.K. (Efthimia Kaprara), F.J.T. and P.R.-G.; visualization, K.S. All authors have read and agreed to the published version of the manuscript.

Funding: The project was financially supported by Stavros Niarchos Foundation and Eastern Macedonia and Thrace Institute of Technology fellowships for assisting young scientists in prototyping innovative products by using cutting-edge technology. Specific measurements received funding from the EU-H2020 research and innovation programme under grant agreement No. 654360 having benefitted from the access provided by ICMAB-CSIC and Universitat Autonoma de Barcelona in Bellaterra-Barcelona within the framework of the NFFA-Europe Transnational Access Activity. Authors would like to thank Anna Esther Carrillo for the experimental assistance during SEM observations and Bernat Bozzo for the support in SQUID measurements. This work was partially funded by Spanish Ministry of Science, Innovation and Universities (MAT2017-85617-R, SEV-2016-0686, RED2018-102626-T) and Comunidad de Madrid (NANOMAGCOST). COST Actions CA17115 (MyWave), and CA17140 (Nano2Clinic) are also acknowledged. The UPF acknowledges the Ministry of Science, Innovation and Universities (MICINN) and the AEI (RYC-2012-10059, MDM-2014-037004, CTQ2013-45433-PFEDER], MAT2016-75362-C3-2-R, AEI-SAF2015-73052-EXP) and the AGAUR (2017 SGR 1054) for financial support.

Institutional Review Board Statement: Not applicable.

Informed Consent Statement: Not applicable.

Data Availability Statement: Please refer to suggested Data Availability Statements in section “MDPI Research Data Policies" at https: / / www.mdpi.com/ethics (accessed on 8 July 2021).

Conflicts of Interest: The authors declare no conflict of interest.

\section{References}

1. Rubia-Rodríguez, I.; Santana-Otero, A.; Spassov, S.; Tombácz, E.; Johansson, C.; De La Presa, P.; Teran, F.J.; Morales, M.D.P.; Veintemillas-Verdaguer, S.; Thanh, N.T.K.; et al. Whither magnetic hyperthermia? A tentative roadmap. Materials 2021, 14, 706. [CrossRef]

2. Etemadi, H.; Plieger, P.G. Magnetic Fluid Hyperthermia Based on Magnetic Nanoparticles: Physical Characteristics, Historical Perspective, Clinical Trials, Technological Challenges, and Recent Advances. Adv. Ther. 2020, 3, 2000061. [CrossRef]

3. Colombo, M.; Carregal-Romero, S.; Casula, M.F.; Gutiérrez, L.; Morales, M.P.; Böhm, I.B.; Heverhagen, J.T.; Prosperi, D.; Parak, W.J. Biological applications of magnetic nanoparticles. Chem. Soc. Rev. 2012, 41, 4306. [CrossRef] [PubMed]

4. Périgo, E.A.; Hemery, G.; Sandre, O.; Ortega, D.; Garaio, E.; Plazaola, F.; Teran, F.J. Fundamentals and advances in magnetic hyperthermia. Appl. Phys. Rev. 2015, 2, 041302. [CrossRef] 
5. Salas, G.; Casado, C.; Teran, F.J.; Miranda, R.; Serna, C.J.; Morales, M.P. Controlled synthesis of uniform magnetite nanocrystals with high-quality properties for biomedical applications. J. Mater. Chem. 2012, 22, 21065. [CrossRef]

6. Verges, M.A.; Costo, R.; Roca, A.G.; Marco, J.F.; Goya, G.F.; Serna, C.J.; Morales, M.P.; Andrés Vergés, M.; Costo, R.; Roca, A.G.; et al. Uniform and water stable magnetite nanoparticles with diameters around the monodomain-multidomain limit. J. Phys. D-Appl. Phys. 2008, 41, 134003. [CrossRef]

7. Simeonidis, K.; Morales, M.P.; Marciello, M.; Angelakeris, M.; De La Presa, P.; Lazaro-Carrillo, A.; Tabero, A.; Villanueva, A.; Chubykalo-Fesenko, O.; Serantes, D. In situ particles reorientation during magnetic hyperthermia application: Shape matters twice. Sci. Rep. 2016, 6, 1-11. [CrossRef]

8. Gonzalez-Fernandez, M.A.; Torres, T.E.; Andrés-Vergés, M.; Costo, R.; de la Presa, P.; Serna, C.J.; Morales, M.P.; Marquina, C.; Ibarra, M.R.; Goya, G.F. Magnetic nanoparticles for power absorption: Optimizing size, shape and magnetic properties. J. Solid State Chem. 2009, 182, 2779-2784. [CrossRef]

9. Cabrera, D.; Coene, A.; Leliaert, J.; Artés-Ibáñez, E.J.; Dupré, L.; Telling, N.D.; Teran, F.J. Dynamical Magnetic Response of Iron Oxide Nanoparticles Inside Live Cells. ACS Nano 2018, 12, 2741-2752. [CrossRef] [PubMed]

10. Di Corato, R.; Espinosa, A.; Lartigue, L.; Tharaud, M.; Chat, S.; Pellegrino, T.; Ménager, C.; Gazeau, F.; Wilhelm, C. Magnetic hyperthermia efficiency in the cellular environment fordifferent nanoparticle designs. Biomaterials 2014, 35, 6400-6411. [CrossRef]

11. Kolosnjaj-Tabi, J.; Di Corato, R.; Lartigue, L.; Marangon, I.; Guardia, P.; Silva, A.K.A.; Luciani, N.; Clément, O.; Flaud, P.; Singh, J.V.; et al. Heat-generating iron oxide nanocubes: Subtle "destructurators" of the tumoral microenvironment. ACS Nano 2014, 8, 4268-4283. [CrossRef] [PubMed]

12. Capeletti, L.B.; Loiola, L.M.D.; Picco, A.S.; da Silva Liberato, M.; Cardoso, M.B. Silica Nanoparticle Applications in the Biomedical Field. In Smart Nanoparticles for Biomedicine; Elsevier: Amsterdam, The Netherlands, 2018; pp. 115-129. ISBN 9780128141571.

13. Bianco, A.; Kostarelos, K.; Prato, M. Applications of carbon nanotubes in drug delivery. Curr. Opin. Chem. Biol. 2005, 9, 674-679. [CrossRef]

14. Li, B.; He, J.; Evans, D.G.; Duan, X. Inorganic layered double hydroxides as a drug delivery system-Intercalation and in vitro release of fenbufen. Appl. Clay Sci. 2004, 27, 199-207. [CrossRef]

15. Shirin, V.A.; Sankar, R.; Johnson, A.P.; Gangadharappa, H.V.; Pramod, K. Advanced drug delivery applications of layered double hydroxide. J. Control. Release 2021, 330, 398-426. [CrossRef]

16. Bi, X.; Zhang, H.; Dou, L. Layered double hydroxide-based nanocarriers for drug delivery. Pharmaceutics 2014, 6, 298-332. [CrossRef]

17. Riaz, U.; Ashraf, S.M. Double Layered Hydroxides as Potential Anti-Cancer Drug Delivery Agents. Mini Rev. Med. Chem. 2013, 13, 522-529. [CrossRef] [PubMed]

18. Barahuie, F.; Hussein, M.Z.; Fakurazi, S.; Zainal, Z. Development of drug delivery systems based on layered hydroxides for nanomedicine. Int. J. Mol. Sci. 2014, 15, 7750-7786. [CrossRef]

19. Wen, J.; Yang, K.; Huang, J.; Sun, S. Recent advances in LDH-based nanosystems for cancer therapy. Mater. Des. 2021, 198, 109298. [CrossRef]

20. Rabiee, N.; Bagherzadeh, M.; Ghadiri, A.M.; Salehi, G.; Fatahi, Y.; Dinarvand, R. ZnAl nano layered double hydroxides for dual functional CRISPR/Cas9 delivery and enhanced green fluorescence protein biosensor. Sci. Rep. 2020, 10, 1-15. [CrossRef]

21. Zhang, L.; Hu, J.; Jia, Y.; Liu, R.; Cai, T.; Xu, Z.P. Two-dimensional layered double hydroxide nanoadjuvant: Recent progress and future direction. Nanoscale 2021, 13, 7533-7549. [CrossRef] [PubMed]

22. Yan, L.; Gonca, S.; Zhu, G.; Zhang, W.; Chen, X. Layered double hydroxide nanostructures and nanocomposites for biomedical applications. J. Mater. Chem. B 2019, 7, 5583-5601. [CrossRef]

23. Nagaraj, V.J.; Sun, X.; Mehta, J.; Martin, M.; Ngo, T.; Dey, S.K. Synthesis, Characterization, and In Vitro Drug Delivery Capabilities of (Zn, Al)-Based Layered Double Hydroxide Nanoparticles. J. Nanotechnol. 2015, 2015, 1-10. [CrossRef]

24. Mourdikoudis, S.; Kostopoulou, A.; LaGrow, A.P. Magnetic Nanoparticle Composites: Synergistic Effects and Applications. Adv. Sci. 2021, 8, 2004951. [CrossRef]

25. Ay, A.N.; Zümreoglu-Karan, B.; Temel, A.; Rives, V. Bioinorganic magnetic core-shell nanocomposites carrying antiarthritic agents: Intercalation of ibuprofen and glucuronic acid into $\mathrm{Mg}$-Al-layered double hydroxides supported on magnesium ferrite. Inorg. Chem. 2009, 48, 8871-8877. [CrossRef] [PubMed]

26. Zhang, H.; Pan, D.; Duan, X. Synthesis, characterization, and magnetically controlled release behavior of novel core-shell structural magnetic ibuprofen-intercalated ldh nanohybrids. J. Phys. Chem. C 2009, 113, 12140-12148. [CrossRef]

27. Zhang, H.; Pan, D.; Zou, K.; He, J.; Duan, X. A novel core-shell structured magnetic organic-inorganic nanohybrid involving drug-intercalated layered double hydroxides coated on a magnesium ferrite core for magnetically controlled drug release. J. Mater. Chem. 2009, 19, 3069-3077. [CrossRef]

28. Zhang, H.; Zou, K.; Sun, H.; Duan, X. A magnetic organic-inorganic composite: Synthesis and characterization of magnetic 5-aminosalicylic acid intercalated layered double hydroxides. J. Solid State Chem. 2005, 178, 3485-3493. [CrossRef]

29. Panda, H.S.; Bahadur, D. Study of the preparation, properties and kinetics of anion release in drug intercalated magnetic nanohybrids. Mater. Res. Bull. 2012, 47, 571-579. [CrossRef]

30. Wang, J.; Zhou, J.; Li, Z.; Song, Y.; Liu, Q.; Jiang, Z.; Zhang, M. Magnetic, luminescent Eu-doped Mg-Al layered double hydroxide and its intercalation for ibuprofen. Chem. A Eur. J. 2010, 16, 14404-14411. [CrossRef] 
31. Pan, D.; Zhang, H.; Fan, T.; Chen, J.; Duan, X. Nearly monodispersed core-shell structural Fe $\mathrm{O}_{4} @$ DFUR-LDH submicro particles for magnetically controlled drug delivery and release. Chem. Commun. 2011, 47, 908-910. [CrossRef]

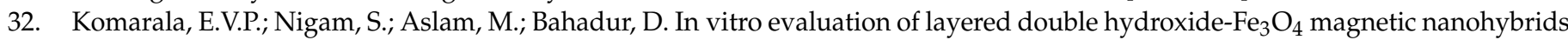
for thermo-chemotherapy. New J. Chem. 2016, 40, 423-433. [CrossRef]

33. Chalkidou, A.; Simeonidis, K.; Angelakeris, M.; Samaras, T.; Martinez-Boubeta, C.; Balcells, L.; Papazisis, K.; Dendrinou-Samara, C.; Kalogirou, O. In vitro application of $\mathrm{Fe} / \mathrm{MgO}$ nanoparticles as magnetically mediated hyperthermia agents for cancer treatment. J. Magn. Magn. Mater. 2011, 323, 775-780. [CrossRef]

34. Mehdaoui, B.; Carrey, J.; Stadler, M.; Cornejo, A.; Nayral, C.; Delpech, F.; Chaudret, B.; Respaud, M. Influence of a transverse static magnetic field on the magnetic hyperthermia properties and high-frequency hysteresis loops of ferromagnetic FeCo nanoparticles. Appl. Phys. Lett. 2012, 100, 052403. [CrossRef]

35. Asimakidou, T.; Makridis, A.; Veintemillas-Verdaguer, S.; Morales, M.P.; Kellartzis, I.; Mitrakas, M.; Vourlias, G.; Angelakeris, M.; Simeonidis, K. Continuous production of magnetic iron oxide nanocrystals by oxidative precipitation. Chem. Eng. J. 2020, 393, 124593. [CrossRef]

36. Luengo, Y.; Morales, M.P.; Gutiérrez, L.; Veintemillas-Verdaguer, S. Counterion and solvent effects on the size of magnetite nanocrystals obtained by oxidative precipitation. J. Mater. Chem. C 2016, 4, 9482-9488. [CrossRef]

37. Lee, J.-H.; Jang, J.-T.; Choi, J.-S.; Moon, S.H.; Noh, S.-H.; Kim, J.-W.; Kim, J.-G.; Kim, I.-S.; Park, K.I.; Cheon, J. Exchange-coupled magnetic nanoparticles for efficient heat induction. Nat. Nanotechnol. 2011, 6, 418-422. [CrossRef]

38. Noh, S.H.; Na, W.; Jang, J.T.; Lee, J.H.; Lee, E.J.; Moon, S.H.; Lim, Y.; Shin, J.S.; Cheon, J. Nanoscale magnetism control via surface and exchange anisotropy for optimized ferrimagnetic hysteresis. Nano Lett. 2012, 12, 3716-3721. [CrossRef]

39. Lavorato, G.C.; Das, R.; Xing, Y.; Robles, J.; Litterst, F.J.; Baggio-Saitovitch, E.; Phan, M.H.; Srikanth, H. Origin and Shell-Driven Optimization of the Heating Power in Core/Shell Bimagnetic Nanoparticles. ACS Appl. Nano Mater. 2020, 3, 1755-1765. [CrossRef]

40. Rivera-Gil, P.; Jimenez De Aberasturi, D.; Wulf, V.; Pelaz, B.; Del Pino, P.; Zhao, Y.; De La Fuente, J.M.; Ruiz De Larramendi, I.; Rojo, T.; Liang, X.J.; et al. The challenge to relate the physicochemical properties of colloidal nanoparticles to their cytotoxicity. Acc. Chem. Res. 2013, 46, 743-749. [CrossRef]

41. Rivera Gil, P.; Oberdörster, G.; Elder, A.; Puntes, V.; Parak, W.J. Correlating physico-chemical with toxicological properties of nanoparticles: The present and the future. ACS Nano 2010, 4, 5227-5231. [CrossRef]

42. Kastl, L.; Sasse, D.; Wulf, V.; Hartmann, R.; Mircheski, J.; Ranke, C.; Carregal-Romero, S.; Martínez-López, J.A.; Fernández-Chacón, R.; Parak, W.J.; et al. Multiple internalization pathways of polyelectrolyte multilayer capsules into mammalian cells. ACS Nano 2013, 7, 6605-6618. [CrossRef]

43. Caballero-Díaz, E.; Pfeiffer, C.; Kastl, L.; Rivera-Gil, P.; Simonet, B.; Valcárcel, M.; Jiménez-Lamana, J.; Laborda, F.; Parak, W.J. The Toxicity of Silver Nanoparticles Depends on Their Uptake by Cells and Thus on Their Surface Chemistry. Part. Part. Syst. Charact. 2013, 30, 1079-1085. [CrossRef]

44. Schweiger, C.; Hartmann, R.; Zhang, F.; Parak, W.J.; Kissel, T.H.; Rivera_Gil, P. Quantification of the internalization patterns of superparamagnetic iron oxide nanoparticles with opposite charge. J. Nanobiotechnology 2012, 10, 28. [CrossRef] [PubMed]

45. Hühn, D.; Kantner, K.; Geidel, C.; Brandholt, S.; De Cock, I.; Soenen, S.J.H.; Riveragil, P.; Montenegro, J.M.; Braeckmans, K.; Müllen, K.; et al. Polymer-coated nanoparticles interacting with proteins and cells: Focusing on the sign of the net charge. ACS Nano 2013, 7, 3253-3263. [CrossRef] [PubMed]

46. Rivera Gil, P.; Hühn, D.; del Mercato, L.L.; Sasse, D.; Parak, W.J. Nanopharmacy: Inorganic nanoscale devices as vectors and active compounds. Pharmacol. Res. 2010, 62, 115-125. [CrossRef]

47. Jin, W.; Lee, D.; Jeon, Y.; Park, D.H. Biocompatible hydrotalcite nanohybrids for medical functions. Minerals 2020, $10,172$. [CrossRef] 